О. П. Дєдов

Київський національний університет будівництва і архітектури, Київ, Україна

\title{
ВИЗНАЧЕННЯ ВПЛИВУ СЕРЕДОВИЩА НА ДИНАМІКУ МАШИНИ НА ОСНОВІ СПЕКТРАЛЬНОГО АНАЛІЗУ
}

\begin{abstract}
Предметом вивчення в статті є математична модель вібраційної системи «машина - середовище» 3 врахуванням властивостей ущільнювального середовища. Метою статті є обгрунтування розрахункової схеми та створення математична модель вібраційної системи «машина - середовище» 3 врахуванням властивостей ущільнювального середовища для оцінки впливу опору середовища при полічастотних коливаннях. Завдання: виконати теоретичні дослідження моделювання і врахування впливу опору середовища при полічастотних коливаннях для ущільнення бетонних сумішей. Використовуваними методами $є$ аналітичні дослідження 3 дискретний і континуальних динамічних систем. Отримані такі результати. Наведені вирази для визначення складових опору середовища при полічастотних коливаннях. Таким чином застосовуючи дані вирази можна оцінити вплив кожної з гармонік вібраційного процесу на рух системи i, відповідно, напружено-деформований стан. Це принципово новий результат і уявлення про можливість створення вібраційних систем нового покоління на такій основі. Висновки. Обгрунтована розрахункова схема та розроблена математична модель вібраційної системи «машина - середовище» 3 врахуванням властивостей ущільнювального середовища; запропонований аналітичний метод визначення впливу оброблюваного середовища на динаміку системи «машина - середовище»; отримані аналітичні залежності для оцінки впливу опору середовища при полічастотних коливаннях.
\end{abstract}

Ключов і слов а : розрахункова модель, деформація, бетонна суміш, частота коливань, вищі гармоніки.

\section{Вступ}

Загальна постановка проблеми та зв'язок 3 практичними завданнями. На сучасному етапі вібраційна техніка будівельної індустрії не в повній мірі відповідає зазначеним викликам галузі. Як правило, вона побудована на використанні лінійних за резонансних режимів. Такі режими не здатні забезпечити мінімальні енерговитратами на протікання технологічних процесів. Обумовлено це відсутністю спеціалізованих віброустановок для формування виробів. Значною розбіжністю існуючих фізичних та математичних моделей, які описують рух вібраційної машини і ущільнювальної бетонної суміші. Тому актуальною $\epsilon$ проблема пошуку більш ефективних конструктивних і технологічних рішень для реалізації високотехнологічних проектів по створенню та дослідженню машин вібраційної дії. Реалізація таких проектів може лежати в площині розробки таких розрахункових моделей, які враховують взаємний вплив машини і середовища на загальний рух системи «машина - середовище».

Аналіз останніх досліджень і публікацій. В роботі [1] наведений аналіз перспективних машин вібраційної дії для ущільнення бетонних сумішей. Зокрема розглянуті машини рамної конструкції 3 просторовими коливаннями. Така конструкція є прогресивним напрямком розвитку вібраційних машин. Однак такі конструкції $є$ малодослідженими з точки зору впливу середовища на конструкцію машини. У більшості випадків проведених теоретичних дослідженнях фізичні і механічні характеристики ущільнювального середовища, які і визначають характер вібраційних машин представлені у вигляді дискретних реологічних моделей. [2]. Моделювання таким чином середовища не дозволяє визначити параметри робочого процесу та дію середовище на конструктивні елементи машини. Робота [3] присвячена дослідженню горизонтальних коливань вібраційної касет- ної установки. Дана робота заслуговує на увагу так як математична модель для дослідження враховує хвильові явища середовища, але коливання та напруження вставних вертикальних пластин не враховуються. Не враховані ефекти виникнення хвильових процесів та відсутня оцінка впливу полі частотних режимів, які виникають при просторовому рухові. Такий метод $є$ достовірним тільки в межах виконаних досліджень та ідентичних за конструкцією та параметрами віброустановок. У роботах [5-7], була запропонована робоча гіпотеза: розробка надійних і найбільш ефективних віброущільнюючих машин для різних умов формування бетонних і залізобетонних виробів забезпечується встановленням і раціональним використанням закономірностей зміни внутрішніх (пружноінерційних і дисипативних) властивостей системи «машина - середовище» в режимі, що $є$ наближеним до вільних коливань вібросистеми. При цьому виконані дослідження передбачали врахування напруженодеформованого стану не лише оброблюваного середовища, а і безпосередньо металоконструкцій машини. Зокрема в роботі [7], визначені частоти і форми коливань запропонованої формоутворюючої конструкції, а також визначений характер руху машини. За результатами досліджень авторами зазначені висновки про наявність складного руху та багато режимність віброущільнюючої машини. Однак вплив середовища на робочі органи машини на різних частотах коливань не оцінювався, а враховувався масовим коефіцієнтом. Також вплив вищих гармонік коливань на процес ущільнення теж відсутній. Проведений аналіз та оцінка досліджень врахування полічастотних засвідчує про наявність проблеми визначення напружень і деформацій при багаторежимному спектрі коливань.

Мета статті - обгрунтування розрахункової схеми та створення математична модель вібраційної системи «машина - середовище» 3 врахуванням властивостей ущільнювального середовища для оцінки впливу опору середовища при полічастотних коливаннях. 


\section{Основна частина}

Для дослідження системи «машина - середовище» використана розрахункова схема (рис. 1). На схемі представлена установка 3 ущільнювальною сумішшю. Установка приводиться в дію змушуючою силою $\mathrm{F}(\mathrm{t})$, під дією сили формоутворююча конструкція здійснює коливання 3 переміщенням робочого органу $\mathrm{z} . \mathrm{Z}(\mathrm{z}, \mathrm{t})$ - переміщення поточного перерізу оброблюваного середовища при коливаннях; Для знаходження опору середовища запишемо аналітичний вираз для елементарного шару бетонної суміші, взявши за вихідну модель середовища, що знаходиться в напружено-деформованому стані.

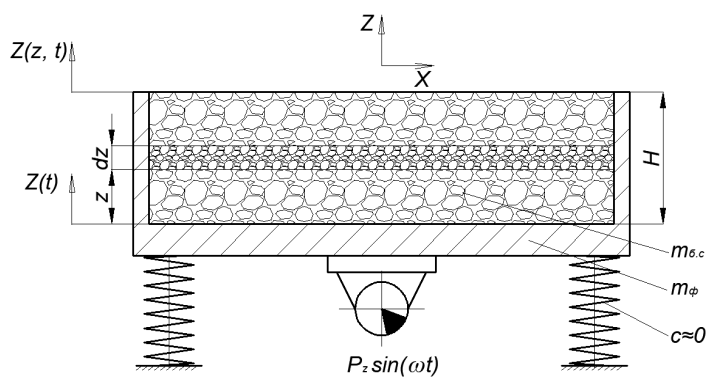

Рис. 1. Розрахункова схема системи «машина - середовище»

При рухові системи у проміжок часу $0 \leq t \leq \tau_{1}$

$$
Z(t)=-z_{1} \sin \left(\pi / \tau_{1} \cdot t\right),
$$

проміжок часу $\tau_{1} \leq t \leq T$ може бути описаний законом:

$$
Z(t)=z_{2} \sin \left(\pi / \tau_{2} \cdot t\right)
$$

де $z_{1}$ й $z_{2}$ - амплітуда коливань ущільнюючої поверхні при $\tau_{1}, \tau_{2}, T$. У випадку, коли період функції $Z(t)$ співпадає з періодом $T$, функція $Z(t)$ може бути записана у вигляді ряду Фур'є:

$$
Z(t)=\sum_{n=-\infty}^{+\infty} z_{n} e^{i n \omega t} ; \omega=2 \pi / T ;
$$

де $z_{n}$ - коефіцієнти Фур'є для функції (3).

Опір середовища, яке ущільнюється можна описати сумою двох складових - активною і реактивною. Реактивна складова опору середовища відповідно до закону Ньютона має вигляд:

$$
R_{p}=m_{6 . c} \ddot{z}
$$

де $\ddot{z}-$ прискорення зони контакту середовища i ущільнювальної поверхні.

Опір середовища з і іншого боку:

$$
R_{p}=-\left.E S \frac{\partial Z}{\partial z}\right|_{z=0}
$$

де $\left.\frac{\partial Z}{\partial z}\right|_{z=0}-$ деформація середовища, яке контактує 3 формоутворюючою поверхнею.

Для визначення прискорення $\ddot{z}$ запишемо хвильове рівняння відносно прискорення:

$$
\ddot{z}=\left.\frac{\partial^{2} Z}{\partial z^{2}}\right|_{z=0}=\left.c^{2} \cdot(1+i \eta) \frac{\partial^{2} Z}{\partial z^{2}}\right|_{z=0}
$$

Враховуючи (4), (5) і (6), отримаємо

$$
m_{\text {б.c }}=-\left.E S \frac{\partial Z}{\partial z}\right|_{z=0} /\left(\left.c^{2} \cdot(1+i \eta) \frac{\partial^{2} Z}{\partial z^{2}}\right|_{z=0}\right) \text {. }
$$

Таким чином, задача знаходження реактивного опору, точніше коефіцієнта $m_{б . c}$, що має розмірність маси й визначає реактивний опір, зводиться до відшукання деформації $\partial Z / \partial z$ і їі похідної $\partial^{2} Z / \partial z^{2}$ на границі $z=0$. Тоді деформація оброблюваного середовища:

$$
\left.\frac{\partial Z}{\partial z}\right|_{z=0}=\left(a_{1}+i \cdot b_{1}\right)\left(Z_{1 n}-Z_{2 n}\right)
$$

Виходячи з граничної умови, що деформація на поверхні оброблюваного середовища відсутня, тобто $\left.\frac{\partial Z}{\partial z}\right|_{z=H}=0$, отримаємо

$$
Z_{1 n} \cdot e^{H\left(a_{1}+i \cdot b_{1}\right) n}-Z_{2 n} e^{-H\left(a_{1}+i \cdot b_{1}\right) n}=0,
$$

звідки

$$
\frac{Z_{1 n}}{Z_{2 n}}=e^{-2 \cdot H\left(a_{1}+i \cdot b_{1}\right) n} .
$$

Вираз для похідної від деформації (8):

$$
\left.\frac{\partial^{2} Z}{\partial z^{2}}\right|_{z=0}=\left(a_{1}+i \cdot b_{1}\right)\left(Z_{1 n}+Z_{2 n}\right) \text {. }
$$

Підставивши отримані вирази (8) й (10) в (7):

$$
\begin{gathered}
m_{\delta . c}=-\frac{\rho \cdot S}{a_{1}+i b_{1}} \frac{\sum_{n=-\infty}^{+\infty} n Z_{2 n}\left(\frac{Z_{1 n}}{Z_{2 n}}-1\right) e^{i n(\omega t)}}{\sum_{n=-\infty}^{+\infty} n^{2} Z_{2 n}\left(\frac{Z_{1 n}}{Z_{2 n}}+1\right) e^{i n(\omega t)}}= \\
=\frac{\rho \cdot S}{a_{1}+i b_{1}} \frac{\sum_{n=-\infty}^{+\infty} n \cdot Z_{2 n}\left(1-e^{2 H\left(a_{1}+i \cdot b_{1}\right) n}\right) \cdot e^{i n(\omega t)}}{\sum_{n=-\infty}^{+\infty} n^{2} \cdot Z_{2 n}\left(1-e^{2 H\left(a_{1}+i \cdot b_{1}\right) n}\right) \cdot e^{i n(\omega t)}} .
\end{gathered}
$$

Для граничних умов:

$$
\left.\frac{\partial Z}{\partial z}\right|_{z=H}=0,\left.Z\right|_{z=0}=Z(t),
$$

одержуємо:

$$
\sum_{n=-\infty}^{+\infty} Z_{2 n}\left(1+e^{2 H\left(a_{1}+i \cdot b_{1}\right) n}\right) \cdot e^{i n(\omega t)}=\sum_{n=-\infty}^{+\infty} z_{n} e^{i n(\omega t)},
$$

тоді $\quad Z_{2 n}=z /\left(1+e^{-2 H\left(a_{1}+i \cdot b_{1}\right) n}\right)$

3 урахуванням (11) формула для визначення $m_{б . c}$ має вигляд:

$m_{\sigma . c}=\frac{\rho \cdot S}{a_{1}+i b_{1}} \frac{\sum_{n=-\infty}^{+\infty} n z_{n} t H\left[H\left(a_{1}+i b_{1}\right) n\right] e^{i n(\omega t)}}{\sum_{n=-\infty}^{+\infty} n^{2} z_{n} e^{i n(\omega t)}}$. 
Оскільки $\dot{z}(\eta)=i \cdot \omega \cdot z(t) ; \ddot{z}=-\omega^{2} z(t)$ й приймаючи, що амплітуда більш високих гармонік менше, ніж для першої гармоніки для прийнятого закону руху, одержуємо після перетворень:

при $0 \leq t \leq \tau_{1}$

$$
m_{\sigma . c}=\frac{2 \cdot \rho \cdot S \cdot t \cdot H\left[H\left(a_{1}+i b_{1}\right) \cdot \tau_{1}\right]}{\left(a_{1}+i b_{1}\right)\left(\tau_{1}+\tau_{2}\right)}
$$

при $\tau_{1} \leq t \leq T$ :

$$
m_{\text {б.c }}=\frac{2 \cdot \rho \cdot S \cdot t \cdot H\left[H\left(a_{1}+i b_{1}\right) \cdot \tau_{2}\right]}{\left(a_{1}+i b_{1}\right)\left(\tau_{1}+\tau_{2}\right)}
$$

Виділяючи дійсну частину у формулах (14) й (15), знайдемо дійсне значення $m_{б . c}$ :

при $0 \leq t \leq \tau_{1}$

$$
m_{\tilde{\sigma . c}}=\frac{2 \cdot \rho \cdot S\left(a_{1} \operatorname{sh} 2 a_{1} H+b_{1} \sin 2 b_{1} H\right) \cdot \tau_{1}}{\left(a_{1}^{2}+b_{1}^{2}\right)\left(\operatorname{ch} 2 a_{1} H+b_{1} \cos 2 b_{1} H\right)\left(\tau_{1}+\tau_{2}\right)} ;
$$

при $\tau_{1} \leq t \leq T$ :

$$
m_{\tilde{\sigma . c}}=\frac{2 \cdot \rho \cdot S\left(a_{1} \operatorname{sh} 2 a_{1} H+b_{1} \sin 2 b_{1} H\right) \cdot \tau_{2}}{\left(a_{1}^{2}+b_{1}^{2}\right)\left(\operatorname{ch} 2 a_{1} H+b_{1} \cos 2 b_{1} H\right)\left(\tau_{1}+\tau_{2}\right)} ;
$$

Прийняте допущення про перевагу першої гармоніки над наступною дало можливість оцінити відмінність в аналітичних виразах для реактивної складової при реалізації гармонійного та несиметричного характерів руху. У випадку внеску більше високих гармонік і при врахуванні, що кожна гармоніка має ще й свою фазу ф. Тоді вираз (13) буде мати вигляд

$$
m_{\tilde{\sigma . c}}=A \cdot \frac{\sum_{n=1}^{\infty} \sum_{n=1}^{\infty}\left(-n^{2} \omega^{2}\right) z_{1 n} e^{i\left(n \omega t+\phi_{n}\right)} t H \frac{k_{1 n} h}{n}}{\sum_{n=1}^{\infty} \sum_{n=1}^{\infty}\left(-n^{2} \omega^{2}\right) z_{1 n} e^{i\left(n \omega t+\phi_{n}\right)}},
$$

де $A=\frac{E S k_{1 n}}{\omega^{2}}$.

3 (18) випливає, що $m_{б . c}$ залежить від часу $\mathrm{t}$, форми імпульсу $\left(z_{1 n}, \phi_{n}\right)$, висоти середовища у напряму вібраційної дії $H$ і частоти $\omega$.

Дійсна частина виразу залежності (18)

$$
\begin{gathered}
m_{\tilde{\sigma} . c}=A \cdot \frac{\sum_{n=1}^{\infty} \sum_{n=1}^{\infty} B \cdot\left(-n^{2} \omega^{2}\right) z_{11} \cos \left(n \omega t+\phi_{n}\right)}{\sum_{n=1}^{\infty} \sum_{n=1}^{\infty}\left(-n^{2} \omega^{2}\right) z_{1} \cos \left(n \omega t+\phi_{n}\right)}= \\
\frac{A \sum_{n=1}^{\infty} \sum_{n=1}^{\infty}\left(-n^{2} \omega^{2}\right) \sqrt{\gamma_{n}^{2}+v_{n}^{2}} \cos \left[n \omega t+\operatorname{arctg}\left(-\frac{\gamma_{n}}{v_{n}}\right)\right] B}{\sum_{n=1}^{\infty}\left(-n^{2} \omega^{2}\right) \sqrt{\gamma_{n}^{2}+v_{n}^{2}} \cos \left[n \omega t+\operatorname{arctg}\left(-\frac{\gamma_{n}}{v_{n}}\right)\right]},
\end{gathered}
$$

де $B=\frac{1}{n} \operatorname{Re}\left[\left[k_{11} t \cdot H\left(k_{1 n} H\right)\right]\right]$.

Після перетворень цієї залежності остаточно можна записати вираз для еквівалентного реактивного опору:

$$
R_{p}=m_{\sigma . c} \ddot{z}
$$

де

$$
m_{\tilde{\sigma} . c}=\frac{A \sum_{n=1}^{\infty} \sum_{n=1}^{\infty} C \cdot \cos \left[n \omega t+\operatorname{arctg}\left(-\frac{\gamma_{n}}{v_{n}}\right)\right] \frac{K_{11}}{n}}{\sum_{n=1}^{\infty} C \cdot \cos \left[n \omega t+\operatorname{arctg}\left(-\frac{\gamma_{n}}{v_{n}}\right)\right]},
$$

тут

$$
\begin{gathered}
C=\left(-n^{2} \omega^{2}\right) \sqrt{\gamma_{n}^{2}+\mathrm{v}_{n}^{2}} \\
K_{11}=\frac{a_{11} \operatorname{sh}\left(2 a_{1 n} H\right)-b_{11} \sin \left(2 b_{1 n} H\right)}{\operatorname{ch}\left(2 a_{1 n} H\right)+\cos \left(2 b_{1 n} H\right)} ; \\
a_{1 n}=\frac{n \omega}{c_{x b} \sqrt[4]{1+\eta^{2}}} \cos \left[\frac{1}{2} \operatorname{arctg}(-\eta)\right] \\
\beta_{1 n}=\frac{n \omega}{c_{x B} \sqrt[4]{1+\eta^{2}}} \sin \left[\frac{1}{2} \operatorname{arctg}(-\eta)\right] .
\end{gathered}
$$

Активний опір:

$$
R_{a}=\left.i E S \eta \frac{\partial Z}{\partial z}\right|_{z=0} .
$$

Прирівнявши отриманий вираз до сили в'язкого опору $F_{e}=b_{e} \cdot z$, маємо:

$$
\begin{aligned}
R_{a} & =i \eta E S \sum_{n=1}^{\infty} k_{1 n} t H\left(k_{1 n} H\right) z_{1 n} e^{i n(\omega t)}=\frac{E S \gamma}{\omega} \\
& =\sum_{n=1}^{\infty} i \cdot n \cdot k_{11} \cdot \omega \cdot t \cdot H\left(k_{1 n} H\right) z_{1 n} e^{i n(\omega t)} .
\end{aligned}
$$

За аналогією з методикою знаходження реактивного опору (21) можна представити у вигляді:

$$
R_{a}=b_{e} \sum_{n=1}^{\infty} i \cdot n \cdot \omega \cdot z_{1 n} e^{i n(\omega t)},
$$

де коефіцієнт еквівалентного опору:

$$
b_{e}=\frac{\frac{E S \gamma}{\omega} \sum_{n=1}^{\infty} \sum_{n=1}^{\infty} n K_{11} t H\left(K_{1 n} H\right) z_{1 n} e^{i n(\omega t)}}{\sum_{n=1}^{\infty} n z_{1 n} e^{i n(\omega t)}} .
$$

Отримані вирази (19) і (22) визначають складові опору середовища при полічастотних коливаннях. Таким чином застосовуючи дані вирази можна оцінити вплив кожної з гармонік вібраційного процесу на рух системи i, відповідно, напружено-деформований стан. Це принципово новий результат і уявлення про можливість створення вібраційних систем нового покоління на такій основі. 


\section{Висновки і перспективи подальшого розвитку у даному напрямку}

1. Обгрунтована розрахункова схема та розроблена математична модель вібраційної системи «машина - середовище» 3 врахуванням властивостей ущільнювального середовища.

2. Запропонований аналітичний метод визначення впливу оброблюваного середовища на дина- міку системи «машина - середовище».

3. Отримані аналітичні залежності для оцінки впливу опору середовища при полічастотних коливаннях.

Створення сучасних машин передбачає реалізацію просторових коливань, тому оцінка впливу середовища на конструкцію машин, робочий режим яких характеризується багаторежимним спектром коливань запланована в подальших дослідженнях.

\section{СПИСОК ЛІТЕРАТУРИ}

1. Нестеренко М. П. Прогресивний розвиток вібраційних установок з просторовими коливаннями для формування залізобетонних виробів / М.П. Нестеренко // Збірник наукових праць (галузеве машинобудування, будівництво). - Полтава: ПолтНТУ, 2015. - Вип. 44. - С. 177 - 181.

2. Chen X. , Wu S., Zhou J. Experimental study and analytical formulation of mechanical behavior of concrete // Construction and Buildings Materials. 2013. 47. P. $662-670$.

3. Маслов О.Г., Молчанов П.О., Нестеренко М.П. Дослідження характеру горизонтально направлених коливань касетної установки // Зб. наук. праць Полтавського національного технічного університету імені Юрія Кондратюка (галузеве машинобудування, будівництво). 2013. Вип. 1 (36). С. 454- 463.

4. Mykola Nesterenko, Aleksandr Maslov, Julia Salenko Investigation of Vibration Machine Interaction With Compacted Concrete Mixture International //Journal of Engineering \& Technology. 2018.7 (3.2) P. 260-264.

5. Nazarenko I.I., Dedov O.P., Svidersky A.T., Ruchinsky N.N. Research of energy-saving vibration machines with account of the stress-strain state of technological environment // IX Int. Conf. HEAVY MACHINERY HM 2017. 2017. Zlatibor, Serbia. P. 14-15.

6. Ivan Nazarenko, Mykola Ruchynskyi, Maksym Delembovskyi.The Basic Parameters of Vibration Settings for Sealing Horizontal Surfaces // Journal of Engineering \& Technology. 2018.7 (3.2) P. 255-259.

7. Ivan Nazarenko, Viktor Gaidaichuk, Oleg Dedov, Oleksandr Diachenko. Investigation of vibration machine movement with a multimode oscillation spectrum // Eastern-European Journal of Enterprise Technolog. 2017. Vol 6, No 1 (90). P. 28 - 36.

Рецензент: д-р техн. наук, проф. К. С. Козелкова, Державний університет телекомунікацій, Харків Received (Надійшла) 17.06.2018 Accepted for publication (Прийнята до друку) 22.08.2018

\section{Определение влияния среды на динамику машины на основе спектрального анализа}

\section{О.П. Дедов}

Предметом изучения в статье является математическая модель вибрационной системы «машина - среда» с учетом свойств уплотнительного среды. Целью статьи является обоснование расчетной схемы и создание математическая модель вибрационной системы «машина - среда» с учетом свойств уплотнительного среды для оценки влияния сопротивления среды при поличастотных колебаниях. Задачи: выполнить теоретические исследования моделирования и учета влияния сопротивления среды при поличастотных колебаниях для уплотнения бетонных смесей. Используемыми методами являются аналитические исследования дискретных и континуальных динамических систем. Получены следующие результаты. Полученные выражения для определения составляющих сопротивления среды при поличастотных колебаниях. Таким образом, применяя данные выражения можно оценить влияние каждой из гармоник вибрационного процесса на движение системы и, соответственно, напряженно-деформированное состояние. Это принципиально новый результат и представление о возможности создания вибрационных систем нового поколения на такой основе. Выводы. Обоснованная расчетная схема и разработана математическая модель вибрационной системы «машина - среда» с учетом свойств уплотнительного среды; предложен аналитический метод определения влияния обрабатываемого среды на динамику системы «машина среда»; получены аналитические зависимости для оценки влияния сопротивления среды при поличастотных колебаниях.

Ключевые слов а: расчетная модель, деформация, бетонная смесь, частота колебаний, высшие гармоники.

\section{Determining the influence of the environment on the dynamics of the machine on the basis of spectral analysis}

$$
\text { O. Dedov }
$$

The subject matter of the study in the article is a mathematical model of the vibration system "machine-environment" taking into account the properties of the sealing medium. The goal of the article is to justify the design scheme and to create a mathematical model of the vibration system "machine-environment", taking into account the properties of the sealing medium for estimating the effect of medium resistance under poly-frequency oscillations. The tasks: to carry out theoretical studies of modeling and taking into account the effect of medium resistance under polyfrequency oscillations for compacting concrete mixes. The methods used are analytical studies of discrete and continual dynamic systems. The following results are obtained. The expressions obtained for determining the components of the medium's resistance under polyfrequency oscillations. Thus, applying these expressions, one can evaluate the influence of each of the harmonics of the vibrational process on the motion of the system and, respectively, the stress-strain state. This is a fundamentally new result and the idea of the possibility of creating a new generation of vibration systems on this basis. Conclusions. The justified calculation scheme and the mathematical model of the vibration system "machine-environment" is developed taking into account the properties of the sealing medium; an analytical method for determining the influence of the medium being processed on the dynamics of the "machine-environment" system; Analytic dependences for the estimation of the influence of the medium's resistance under polyfrequency oscillations are obtained.

Keywords: design model, deformation, concrete mixture, oscillation frequency, higher harmonics. 